\title{
PERSPECTIVAS, HÁBITOS E FUNCIONALIDADE DE IDOSOS EM DOIS ESPAÇOS DE INCLUSÃO SOCIAL
} PERSPECTIVES, HABITS AND FUNCTIONALITY OF ELDERLY IN TWO SOCIAL INCLUSION SPACES

\author{
Rosvita Beatriz Ullmann Marcon¹ (D), Marcello Ávila Mascarenhas' ${ }^{1}$ (D), Cleber Gibbon Ratto ${ }^{1}$ (D)
}

\begin{abstract}
RESUMO
Este estudo teve como objetivo analisar, de forma comparativa, dois projetos sociais com pessoas idosas em situação de boa funcionalidade, observando hábitos de vida, funcionalidade social e familiar, perspectivas de vida e futuro, em um clube social e em uma ONG, localizados na cidade de Porto Alegre, RS. Os dados foram analisados por método descritivo, tendo sido uma pesquisa transversal e exploratória, de junho a setembro de 2019. Foi aplicado um questionário objetivo com múltiplas escolhas, que consistiu em 15 perguntas. Participaram 15 pessoas idosas de cada instituição, com idades a partir de 60 anos. A pesquisa beneficiou os idosos, abordando amplitude de questões nas quais estes estão inseridos. Os idosos reconheceram que costumam se moldar às disponibilidades dos contextos sociais, sem questionar. Puderam absorver novos conhecimentos sobre o que os envolve e se deram conta de que as instituições favorecem em sua qualidade de vida, e que é imprescindível que haja multidisciplinaridade para que consigam suprir suas necessidades na íntegra.
\end{abstract}

Palavras-chave: Espaços, Idosos, Inclusão, Social, Instituições.

\begin{abstract}
The objective of this study is to analyze comparatively two social projects with the elderly in a situation of good functionality, concerning their habits, social and familiar functionality, and life perspectives. The social projects are an NGO and a social club in Porto Alegre/RS. Data was analyzed by a descriptive method. The transversal exploratory research took place from June to September 2019. A multiple choice questionnaire composed of 15 questions was applied to 15 elderly from the age of 60 from both of the institutions. The research benefitted the elderly asking several questions regarding their environment. The elderly recognized their tendency to shape themselves to the availability of the social contexts without questioning. They were able to learn more about the places they are inserted into and they noticed that the institutions help improve their quality of life and that multidisciplinarity is key to fully supply their needs.
\end{abstract}

Keywords: Spaces, Elderly, Social, Inclusion, Institutions.

${ }^{1}$ Centro Universitário Metodista- IPA

Autor Correspondente: Rosvita Beatriz Ullmann Marcon

E-mail: rosi.marcon10@hotmail.com

Recebido em 17 de Jul de 2020 | Aceito em 18 de Fev de 2021. 


\section{Introdução}

O Brasil passa por uma fase de transição demográfica, em que os idosos estão prolongando o seu tempo de vida, e estes, passarão a ocupar maior fatia nas estatísticas da população brasileira (Barsi Filho, Leal \& Portela, 2015). Os estudos científicos quanto às modificações dos indicadores definiram essa "transição demográfica" como sendo a mudança no transcorrer do tempo, cujo processo inicial tem sido uma queda da fecundidade, que é consequência de vários fatores, tais como projetos de educação sexual, planejamento familiar, utilização de métodos contraceptivos, maior participação da mulher no mercado de trabalho, expansão da urbanização, entre outros, e que, em longo prazo, vem repercutindo no declínio do número de habitantes (Guerra et al., 2019; Neri, 2001; Castiel, 2016). Para Vasconcelos e Gomes (2012), "ainda que os níveis de fecundidade tenham declinado abaixo do nível de reposição na maior parte do país, não se alcançou o equilíbrio demográfico, com baixos níveis de mortalidade e natalidade". Isso indica que haverá menor número de nascimentos enquanto a população idosa prolonga seu tempo de vida, delineando-se um Brasil que está envelhecendo, o que nos convoca a pensar em novos modos de qualificar e facilitar a vida das pessoas idosas.

Esse é, então, o fenômeno do processo de envelhecimento e a forma como vem se desenhando. Esse fenômeno caracteriza-se também pela sua universalidade, uma vez que se manifesta em diversos países, estando o envelhecimento condicionado às conjunturas em que se apresenta e àquilo que o antecede, mostrando, entretanto, diferenças no que tange aos países desenvolvidos e aos em desenvolvimento. No Brasil, um país em desenvolvimento, essa transição demográfica está basicamente definida pelas particularidades históricas em que se insere. Para Whitaker (2010), a sociedade precisa ser educada para compreender o envelhecimento sobre esse novo prisma. E, segundo ela, está na hora de repensar as atitudes que infantilizam o idoso e o assistencialismo, este que, principalmente nas camadas exploradas, trata-o como indigente, transformando-se em esmola ou favor. Cabe ressaltar, ainda, que, conforme a Lei $n^{\circ} 10.741$ (Brasil, 2003), há poucas políticas públicas que amenizam essa fase da existência, em relação às quais se configuram direitos humanos estabelecidos como direitos sociais em diplomas legais.

Por muito tempo, o envelhecimento foi visto como a antítese do desenvolvimento, sendo respaldado pela geriatria e, portanto, muitos praticantes e pesquisadores em gerontologia consideravam a velhice como sinônimo de doença. Sucedeu-se um período em que a visão pessimis- ta tradicional conviveu com um otimismo excessivo, que tomava o desenvolvimento como um processo permanente e que indicava possibilidades quase ilimitadas de mudanças positivas com o passar da idade (Neri, 2001).

Contudo, ao longo das últimas décadas, foram apontadas novas formulações quanto à possibilidade de uma boa e saudável velhice. Propõe-se, então, medidas para a recuperação da dignidade dessa importante fase da vida, a partir da educação da nova sociedade no que tange a suprir necessidades, não apenas básicas, mas de novas perspectivas e entretenimento. Urge que o Brasil se organize em políticas públicas que garantam a seguridade social das pessoas idosas, efetivamente englobando saúde, previdência e assistência social.

Como qualquer outra pessoa, a maioria dos idosos querem permanecer ativos e ter o seu papel na sociedade, sendo a inclusão no social a maneira mais adequada de preservar cidadania e bem-estar ao idoso. Faz-se necessária a discussão da reforma da previdência, cujo teto de gastos impacta tanto no investimento quanto na execução das políticas públicas; implicando em seguir as diretrizes para o cuidado das pessoas idosas no Sistema Único de Saúde (SUS), cuja proposta de 2014 é a de "modelo de atenção integral", tratando a pessoa idosa de acordo com as suas especificidades; também o investimento na atenção integral através de diferentes programas, entre outros. Em algumas áreas já se avançou, porém, em outras, estamos estagnados. Castiel (2016) afirma que através da transição demográfica mais pessoas chegarão aos 65 anos ou mais, e essa situação, em que as pessoas idosas viverão mais tempo, faz com que o Governo deva repensar suas políticas voltadas para idosos, nas mais diferentes áreas, como, por exemplo, em relação ao sistema previdenciário (Castiel, 2016).

Assim, no que tange o envelhecimento humano, tem-se aqui o objetivo de analisar, de forma comparativa, dois projetos sociais com idosos, observando hábitos de vida, funcionalidade social e familiar, perspectivas de vida e futuro, em um clube social e em uma Organização não Governamental (ONG), localizados na cidade Porto Alegre RS. A intenção é discutir quanto às lacunas e aos avanços, primando por contribuir na disseminação da informação. O intuito não é favorecer somente aquele que passa pelo processo do envelhecimento, mas alertar todos os que estão envolvidos, de certa forma, no cuidado, no convívio e na responsabilidade para com o público idoso. Essa proposta surge frente à necessidade de reestruturação dos espaços de circulação, exigindo-se sua ampliação para o alcance das especificidades da pessoa idosa, bem como a capacitação dos profissionais que exercerão algum pa- 
pel relevante na multidisciplinariedade (Barsi Filho, Leal \& Pessoa, 2015), isso porque o cuidado deve também agregar conhecimento, atender às expectativas da pessoa idosa e atuar em suas peculiaridades, que requerem mudanças na forma de atuação e na organização do trabalho, e demandam alta complexidade de saberes (Silva \& Trad, 2005).

Nessa perspectiva, reconhece-se a necessidade da configuração de novos campos de representação (espaços públicos e infraestruturas), bem como a criação e a ampliação de espaços múltiplos nas esferas social e cultural (políticas públicas) que possam favorecer a interação e inclusão no social. É necessária também, a prática de atividades para melhor qualidade de vida, sendo que, para nos certificarmos das necessidades existentes, achamos melhor ouvirmos o próprio idoso. Porém, por mais que se perceba que existam órgãos e equipes envolvidos e empenhados em gerar melhorias que venham favorecer aos idosos, ainda é preciso avançar muito na questão de pesquisas que envolvam essas inúmeras nuances (como manter os idosos ativos, promover o bem-estar físico, emocional e social, entre outros). Diante do exposto, optou-se por realizar a presente pesquisa nestes dois projetos vinculados à política social, sendo estes espaços por onde este circula e convive a fim de se obter um entendimento quanto a procedimentos e possibilidades oferecidas aos idosos no presente momento. As respostas foram obtidas através de um questionário respondido pelos próprios idosos, que são os participantes e favorecidos com o projeto. Este estudo teve, assim, o objetivo de analisar de forma comparativa esses dois projetos sociais de idosos e, através da análise das respostas, entender em que áreas pode haver avanços favoráveis aos analisados.

\section{Material e Métodos}

Neste trabalho, foi realizado um estudo descritivo, transversal e exploratório, características estas que foram escolhidas para fundamentar o estudo devido à sua abrangência, visando esclarecer e chegar às respostas das nossas perguntas de pesquisa e, direcionando a relações que julgamos essenciais para com a velhice. Houve a possibilidade de um olhar peculiar, maior proximidade, envolvendo a realidade da população específica de idosos, que se tornam vulneráveis nessa fase da vida. Para maior entendimento e esclarecimento, passaremos a falar um pouco de cada uma das características, sob o olhar de alguns autores que nos trazem subsídios para estabelecermos critérios que sustentam a nossa escolha e direcionamento.
Conceitua-se a pesquisa descritiva como a que leva a observar, registrar, analisar e ordenar os dados, sem manipulá-los, isto é, sem interferência do pesquisador. Logo, o que se defende e busca aqui é a percepção do idoso inserido num contexto social (espaço urbano), interagindo, preservando uma funcionalidade ativa, dando continuidade a novas descobertas e fazendo trocas, usufruindo dos seus direitos, e não isolado, retirado e se restringindo ao "confinamento e abandono" do seu lar ou de casas geriátricas, esperando chegar o dia da sua finitude. Percebemos que o idoso continua sendo desrespeitado nesses espaços urbanos, os quais ainda são inadequados (filas, sistema de saúde, processos burocráticos, ambientes sociais restritos e outros) e continuam tratando o idoso como alguém de menor valia por já não ter as mesmas habilidades e discernimento de quando era jovem. Acreditamos que, enquanto o idoso estiver ativo, fazendo trocas e ocupando-se com algo, estará dando continuidade à vida e se restringirá o espaço para doenças físicas e mentais.

Os estudos transversais, por sua vez, consistem em uma ferramenta de grande utilidade para a descrição de características da população, levando à identificação de grupos de risco, delineando a ação e o planejamento em saúde. Quando utilizados de acordo com suas indicações, vantagens e limitações podem oferecer valiosas informações ao avanço do conhecimento científico (Bastos \& Duquia, 2007). Para Gordis (2017), o que envolve, essencialmente, a condução do estudo transversal são as seguintes etapas: definição de uma população de interesse; estudo da população por meio da realização de censo ou amostragem de parte dela; e determinação da presença ou da ausência do desfecho e da exposição para cada um dos indivíduos estudados.

Em Pereira (1995), existe a afirmativa de que os estudos transversais são adequados para responder às perguntas: Quais são as frequências do fator de risco e do desfecho em estudo? Existe associação entre o fator de risco e o desfecho em questão? E, segundo Gil (2009, p. 41), a pesquisa exploratória, é a que "tem como objetivo proporcionar maior familiaridade com o problema", ou seja, uma vez que teve que responder a questões que foram aflorando, este prima também pela busca da solução de um problema, com o qual se passou a ter maior familiaridade, tornando-o mais explícito e fazendo com que viesse ao encontro da nossa hipótese existente. Para coletar esses dados, são utilizadas técnicas específicas, tais como: entrevista, formulário, questionário, observação e leitura analítica (Almeida, 1996). 
De acordo com Lopes (1999), os três maiores problemas teóricos de uma pesquisa estatística com base em uma amostra são os seguintes: especificação, projeto e avaliação. A especificação consiste em determinar o erro máximo que pode ser cometido; o projeto, em produzir a confiabilidade desejada ao menor custo possível e leva a utilizar as facilidades físicas e os recursos humanos disponíveis. Por fim, a avaliação conduz à verificação das diferenças entre os vários procedimentos utilizados para a comparação de resultados. Essa definição foi importante e ajudou no formato da avaliação e busca dos resultados do presente estudo, assim como as anteriores descritas.

Nesse contexto e entendimento da presente pesquisa, objetivou-se conhecer a percepção vivencial de 15 idosos, com idades a partir de 60 anos, em cada uma das duas instituições pesquisadas, através de um questionário de 15 perguntas, programando em torno de oito minutos para responder a cada questão objetiva, mas com o propósito de respeitar a velocidade de cada participante, por se tratar de idosos, totalizando duas horas para a pesquisa (para responder ao questionário) e tendo três pessoas para auxiliar mediante eventuais dúvidas - em Porto Alegre, RS. A pesquisa contemplou as diretrizes e as normas regulamentadoras previstas pela Resolução 466/16 do CNS e pelos Comitês de Ética em Pesquisa (CEP), sendo que a coleta de dados ocorreu após aprovação do Comitê de Ética em Pesquisa do Centro Universitário Metodista - IPA - Parecer Consubstanciado do CEP no 3.213 .640 CAAE: 10999819.5.0000.5308.

Iniciamos com a definição dos locais, em seguida, fizemos o contato e foi permitida a visitação às instituições, a fim de conhecê-las. Houve a possibilidade de obter alguns manuais com as programações e as principais informações de como esses locais operam através de suas práticas. Posteriormente, surgiu a oportunidade da inserção dos pesquisadores nas dinâmicas, em vários grupos de idosos, ao que se observaram os procedimentos e percebeu-se que as instituições conseguem diversificar as atividades, integrando as pessoas idosas num contexto social e fazendo com que estas se sintam ocupadas, valorizadas e inseridas num ambiente interativo.

Foi realizada uma apresentação inicial, conscientizando sobre várias questões que envolvem o envelhecimento $\mathrm{e}$ a necessidade de que este seja vivido de forma preventiva (no que tange à saúde pública, medicação, moradia, alimentação, transporte, interação social, acompanhamento, continuidade de aprendizagens etc.). Os idosos pesquisados foram receptivos e consideraram o momento agradável, tendo sido de trocas, questionamentos, reflexões e informações. Eles foram informados sobre o assunto da pesquisa, com esclarecimentos sobre seu teor e o que se pretendia; tomaram ciência quanto ao "termo de consentimento livre e esclarecido - TCLE" conforme a Resolução 466/12, através do termo o participante da pesquisa tem garantido seus direitos e compreensão de sua total segurança

Percebeu-se que ficaram entusiasmados e gostaram da ideia de representarem a categoria de idosos. No encontro posterior, houve a aplicação do questionário, ao que se presenciou um caso em que a participante se sentiu mobilizada emocionalmente ao ter que refletir e responder sobre as suas questões pessoais. Ela recebeu assistência de profissionais da área da psicologia e se restabeleceu, sendo que não ocorreu trauma de maior gravidade. Outra participante com câncer metastático, oportunamente, conseguiu falar sobre o seu problema e foi acolhida por todos.

A escolha dos participantes da pesquisa foi mediante a disposição e o interesse manifestados nesses contatos iniciais. O público se restringiu basicamente a mulheres, sendo que teve apenas um homem numa das instituições que se dispôs a responder ao questionário. As questões foram de múltipla escolha, objetivas e com espaço para observações. Todos os dados foram analisados de acordo com cada dimensão e questão, comparando depois cada realidade das duas instituições. Esse contato com os idosos favoreceu a pesquisa, uma vez que se criou um vínculo e, dessa forma, os participantes se viram destemidos para responderem ao questionário de acordo com aquilo que realmente sentem diante das situações e dos ambientes sociais, alegando desconforto pelas dificuldades e morosidade em alguns processos sociais, desde atendimento a outras áreas ou fatores relacionados à sua faixa etária, mas com as instituições, no geral, estavam confortáveis.

A análise estatística dos dados obtidos através dos questionários foi compilada em Excel 2016, para a realização das estatísticas descritivas. Quanto às variáveis quantitativas, foram realizados cálculos de média aritmética e desvio padrão. As variáveis qualitativas foram realizadas em análise da frequência absoluta e relativa, e se construiu quadros de distribuição de frequência.

\section{Resultados e Discussão}

Primando por estruturar adequadamente a pesquisa, buscamos também, na teoria de alguns autores, estudos que favoreceram sua consistência e, para tanto, trazemos Booth (2005), que questiona sobre o que a pesquisa pode 
representar. $\mathrm{O}$ autor responde que busca uma resposta, a qual muitos poderão considerar idealista, mas que promove a satisfação de descobrir algo novo, algo que ninguém mais conhece, desafiando-nos e contribuindo para o enriquecimento do conhecimento humano. Isso tudo exige mais do que a estruturação dos espaços comuns e a qualificação profissional, mas é preciso também pensar nas metodologias para gerir esses espaços sociais, a fim de que todas as pessoas envolvidas possam se beneficiar. Nesses níveis de atenção à saúde do idoso, impõe-se a necessidade do trabalho em equipe, favorecendo uma abordagem integral dos fenômenos que interferem na saúde. Essa ação multiprofissional pressupõe a realização de um plano que envolve os cuidados e é compartilhado pelos vários profissionais de saúde (Besse, Cecílio \& Lemos, 2014).

No olhar de Maia et al. (2013), um profissional que busca trabalhar na área de saúde deve ter em mente o perfil que essa atividade exige, envolvendo trocas, que devem estar presentes na quase totalidade de funções de outros setores, sejam eles públicos ou privados. Peduzzi (2009) alerta que diferentes critérios são utilizados para analisar as modalidades de equipe: qualidade da comunicação, especificidades dos trabalhos especializados, questionamento da desigual valoração social dos diferentes trabaIhos, flexibilização da sua divisão, autonomia profissional de caráter interdependente e construção de um projeto assistencial comum. Isso tudo favorece no que tange ao atendimento e ao bem-estar do idoso.

Entendemos, assim, que as questões relacionadas aos idosos carecem de maior visibilidade, sendo o grande desafio a área da saúde coletiva, que necessita de conhecimento sobre as especificidades que envolvem a terceira idade em nosso país, quanto aos direitos adquiridos e que foram transformados em "Estatuto do Idoso", e que são respeitados por poucos, não proporcionando ao idoso um envelhecimento digno. É preciso ciência de que o processo do envelhecimento está associado a alterações estruturais de espaços físicos (para o conforto, as mobilizações e as interação) e funcionais (tudo o que envolve a saúde física e mental), exigindo dedicar maior atenção aos cuidados para com a saúde, prevenindo o desenvolvimento de doenças como as crônicas, as quais podem gerar incapacidades. $\mathrm{O}$ artigo 30 do Estatuto do Idoso estabelece como "obrigação da família, da comunidade, da sociedade e do Poder Público assegurar ao idoso, com absoluta prioridade, a efetivação do direito à vida, à saúde, à alimentação, à educação, à cultura, ao esporte, ao lazer, ao trabalho, à cidadania, à liberdade, à dignidade, ao respeito e à convivência familiar e comunitária" (Lei 10.741/2003-Estatuto do Idoso-Senado Federal). É, portanto, de extrema importância trabalhar para que seja desmistificado o discurso que desvaloriza o envelhecimento e caracteriza o idoso como um "fardo a ser carregado", de modo a proporcionar maior dignidade aos "futuros idosos".

Logo, o idoso passa a ter algumas necessidades que devem constar como conceitos prioritários, não bastando, para tanto, a criação de manuais ou campanhas de conscientização, mas devendo fazer valer-se nas práticas profissionais e sociais (estruturação dos espaços físicos para atendimento e interação, habilitando profissionais e envolvendo a própria família e órgãos responsáveis), favorecendo, dessa forma, os convívios e a qualidade de vida das pessoas idosas. E, para fazer valer todas as ações necessárias ao envelhecimento saudável e com qualidade de vida, é preciso repensar e redesenhar o cuidado com idosos, enquanto indivíduos ainda com potencial realizador, e atendo-se também às suas especificidades, envolvendo as políticas públicas e visando o aprimoramento da legislação (uma das dificuldades para a implementação está na pouca estrutura dos chamados conselhos de direitos da pessoa idosa, que atuam na articulação e na fiscalização de políticas públicas em âmbito local). Isso trará benefícios aos idosos e, também, aumentará a qualidade e a sustentabilidade do sistema de saúde. Dessa forma, se caminhará em direção a uma provável solução que favoreça aos envolvidos.

Segundo Torres e Santos Sá (2008), com quem corroboramos por virem ao encontro do nosso objetivo de pesquisa, é possível afirmar que o envelhecimento não é igual para todos e, para além da idade, depende também das condições objetivas de vida em fases anteriores do seu ciclo vital, do acesso a bens e serviços, bem como da cobertura da rede de proteção e atendimento social. Os autores afirmam que os estudos sobre a velhice e o processo de envelhecimento abarcam as diversas possibilidades de pensar o lugar social ocupado pelo idoso na realidade brasileira. A velhice tem sido tratada como um mal necessário, da qual a humanidade não tem como escapar. Por esse princípio, o idoso também é tratado como um mal necessário, como alguém que cumpriu sua função social: tendo trabalhado, cuidado da família, contribuído para a educação dos filhos, restando, assim, esperar pela finitude da vida. Os autores comentam ainda que se observa que, com o avanço das pesquisas na área da saúde e o acesso da população idosa aos diversos serviços, a população, de um modo geral, chega aos 60 anos com a possibilidade de viver mais tempo (e com qualidade de vida) em relação ao que se vivia há 20 anos ou mais. 
Os processos associados ao envelhecimento da população vêm contribuindo para gerar uma reflexão sistemática sobre o tema da velhice no Brasil e, também, sobre a relevância do trabalho em equipe quanto à saúde do idoso. Os profissionais da saúde podem colaborar para melhorar a qualidade de vida da pessoa idosa por meio das questões interdisciplinares e da atuação multiprofissional e, através do trabalho em equipe, preparar os idosos para viverem as mudanças associadas ao envelhecimento, de forma ativa e saudável. Existe a necessidade de "integração das disciplinas e das profissões entendidas como imprescindíveis para o desenvolvimento das práticas de saúde a partir da nova concepção biopsicossocial do processo saúde-doença" (Peduzzi, 2009). É fundamental investir em ações de prevenção ao longo de todo o curso de vida, em virtude do seu potencial para "resolver os desafios de hoje e, de forma crescente, os de amanhã" (Guerra et al., 2008). Essas questões todas estão presentes na vida do idoso e precisam ser trazidas, pensadas, pesquisadas e exigem ações de todos nós, cidadãos, para que ele possa ocupar os espaços e usufruir dos seus direitos. A pesquisa mostra o quanto esses idosos que estão interagindo conseguem se sentir valorizados e, entre o grupo, vão passando informações e experiências que têm sido positivas, junto das instituições, somando forças para conquistar aquilo que Ihes deve ser destinado por direito.

Os participantes idosos (acima de 60 anos, o que para efeitos de formulação de políticas públicas, pode variar segundo as condições de cada país, não sendo a idade cronológica um marcador preciso para a alteração que acompanha o envelhecimento, variando as condições de saúde, nível de participação na sociedade e nível de independência das pessoas idosas em diferentes contextos) deste estudo têm consciência da sua condição de pessoas idosas, percebendo o quanto a integração nos ambientes sociais Ihes é favorável, uma vez que os coloca em situação de igualdade, sentindo, assim, as instituições como um local em que são acolhidos e no qual conseguem se ocupar, mas também manifestam lacunas no que tange à diversidade de atividades, desfavorecendo, em muitas situações, quanto a opção de escolha; tendo surgido este descontentamento no item "sentidos da participação no programa pesquisado". Percebemos que algumas pessoas idosas são mais atuantes e dispostas a aprenderem coisas novas, enquanto que outras demoram um pouco mais a se moldar ao contexto grupal. Nesse quesito, é relevante dizer também, que alguns possuem menos mobilidade e capacidades físicas e intelectuais para acompanharem os grupos, em relação a outros que são mais dinâmicos e participativos, porém, nestes locais pesquisados, nenhum deixa de ter a assistência e o cuidado necessários para permanecer integrado e ativo.
Entendemos que os idosos e os seus familiares não podem ser vistos como receptores passivos de serviços de saúde. Eles precisam e devem ser agentes ativos na construção de um novo cuidado à saúde, devendo participar e serem apoiados nesse sentido. Esse cuidado envolve informações atualizadas, instruções compartilhadas e rede de atenção integrada de forma a atuar na minimização dos efeitos incapacitantes das doenças e na diminuição do risco de óbitos precoces (Carboni \& Reppetto, 2007). 0 público idoso merece um olhar diferenciado que envolve o cuidado e o suporte necessário ao seu bem-estar, favorecendo a vida ativa e com boa funcionalidade. Para tanto, é importante que se atue preventivamente e que todos se envolvam nessa causa que diz respeito às pessoas idosas.

Para aprofundar o entendimento desta pesquisa, sugerimos que seja lido o "Relatório Mundial de Envelhecimento e Saúde" (OMS, 2015), que faz uma abordagem sobre envelhecimento saudável aqui discutido, destacando que ele é mais do que apenas a ausência de doença e, portanto, a manutenção da habilidade funcional é importante e o enfoque social recomendado para abordar o envelhecimento da população requer uma transformação dos sistemas de saúde que substitua os modelos curativos baseados na doença, bem como aborda as mudanças associadas ao envelhecimento no contexto de todo o curso da vida. O idoso é avaliado quanto à capacidade intrínseca, que se refere ao composto de todas as capacidades físicas e mentais que um indivíduo pode apoiar-se em qualquer ponto no tempo, e a outra capacidade, a extrínseca são os ambientes nos quais vivem e suas interações neles. Os ambientes sociais incluem lar, vizinhança e comunidade, que podem afetar diretamente na saúde e impor barreiras ou incentivos que influenciam as decisões e os comportamentos.

O relatório também constrói um quadro estratégico para falar sobre a ação pública quanto a percepções e suposições de saúde e envelhecimento baseadas em estereótipos ultrapassados, exigindo perspectivas atuais. As populações idosas são caracterizadas por grande diversidade e as políticas devem ser estruturadas de forma que permitam um maior número de pessoas a alcançarem trajetórias positivas do envelhecimento e devem servir para quebrar as barreiras que limitam a participação social contínua e as contribuições de pessoas idosas. Outras questões abordadas são os sistemas de saúde que devem se moldar às necessidades dessa população; os serviços e sistemas orientados em torno da capacidade intrínseca; profissionais adequadamente treinados com habilidades gerontológicas e geriátricas básicas; os ambientes favoráveis à população de idosos, combatendo a discriminação etária e proporcionando autonomia; o aprimoramento na 
medição, no monitoramento e na compreensão de questões e tendências relacionadas à idade; e o fato de que a idade avançada não implica necessariamente em dependência e discriminação etária. As mudanças que constituem e influenciam o envelhecimento são, portanto, amplas e complexas.

Destarte, reconhece-se a necessidade da sociedade em geral e dos profissionais de saúde de estimular a inclusão dos idosos brasileiros na sociedade, em prol de uma meIhor qualidade de vida e de saúde, física e mental. Dessa forma, é prazeroso participar de ações em que se adota um estilo de vida específico, com o viés de um estímulo à participação social, devido ao engajamento em relações significativas no que tange o espaço familiar, inserido na comunidade, promovendo o exercício da autonomia; favorecendo também, o engajamento dos idosos em grupos específicos e possibilitando a realização de atividades manuais, a fim de dar continuidade à criatividade, tendo o sentimento de liberdade, e a satisfação em compartiIhar histórias de vida, sempre respeitando as limitações de cada indivíduo (GUERRA et al., 2013).

A ONG é um lugar que acolhe pessoas com vulnerabilidade social. As estruturas físicas são amplas, apesar do estado de má conservação. Nesse local, poderiam ser ampliados muitos projetos sociais, do mesmo modo que o do grupo de idosos da pesquisa, o qual está funcionando relativamente bem. Nas estruturas que existem nesse local, funcionam várias outras ONGS que envolvem questões políticas e, no período de realização da pesquisa, presenciamos outros projetos muito bons sendo extintos. Isso é impactante e cada vez mais é fato que as pesquisas são muito boas e apontam questões relevantes por haver um estudo criterioso e consistente. Foi possível perceber que as equipes multidisciplinares precisam se unir, a fim de somar forças e conseguir, dessa forma, beneficiar mais pessoas ou grupos, assim como fazer trocas que possam favorecer aos idosos.

$\mathrm{Na}$ outra instituição, o clube social, encontramos um grupo de idosos com o nível cultural mais elevado, demonstrando, assim, algumas características diferentes do anterior, mas não divergentes no que tange às possibilidades ao grupo etário. Nessa instituição, as idosas, além de possuírem maior qualificação e de usufruírem também de maior diversidade quanto ao preparo físico que o clube oferece, são favorecidas pelas palestras ministradas por médicos, nutricionistas, assistentes sociais, psicólogos, dentistas, escritores, entre outros, que envolvem diversos temas, como gastronomia, saúde, estética e cuidados do corpo, cultura, espiritualidade, relacionamento, entre muitas outras áreas. Essas idosas também gostam da ideia de fazer passeios e conhecer outros lugares.

A programação do clube é antecipada semestralmente. Após todas as palestras e dinâmicas semanais, os idosos têm em torno de meia hora para a confraternização, na qual sempre recebem lanches, elaborados com cuidado para que sejam produtos saudáveis e naturais, acompanhados por sucos e chás. Ao analisar a chegada e a saída dessas idosas, percebeu-se que todas são conhecidas pelo nome usual, e os funcionários que atuam com elas sabem as características peculiares de cada integrante. Esse grupo de idosos não é restrito aos associados do clube, sendo acolhidos todos os idosos que fizerem a sua inscrição. Foi observado, nesse local, que muitas das participantes da pesquisa são funcionárias públicas aposentadas que desejam continuar se ocupando e interagindo para com o seu entorno. A grande maioria possui curso superior, inclusive, esse grupo foi muito questionador e interagiu bastante, somando através da verbalização de suas vivências.

O interesse em pesquisar sobre as pessoas idosas foi despertado a partir da divulgação da alteração da transição demográfica, que indica que, supostamente, todos os países precisarão adotar políticas mais ousadas para lidar com as mudanças demográficas nos próximos períodos. Assim, pensou-se na inserção do público idoso no que diz respeito ao sentido e à continuidade da vida, que deve ser com qualidade, de forma ativa e com boa funcionalidade, resultantes de hábitos saudáveis e adequados, em ambas as instituições. É preciso avaliar essas perspectivas e estruturar as possibilidades que possam favorecer a qualidade de vida e a inclusão das pessoas idosas no social, uma vez que o envelhecimento traz como um dos seus principais problemas a exclusão social. Certamente, hoje, os idosos estão se cuidando mais no que tange a práticas alimentares, cuidados físicos e exames médicos assíduos, procurando também ativar mais o cérebro, buscando informações e alterando consideravelmente a sua rotina, o que modifica a ideia de enquadrar o idoso no contexto de pessoa inútil, improdutiva e doente. $O$ questionário iniciou com uma pergunta que é considerada de primordial importância no contexto da velhice, quanto aos hábitos de vida, envolvendo as atividades práticas que dão maior prazer neste período, e, como e onde este passa a maior parte do seu tempo, o que gerou os resultados investigados (Quadro 1). 


\section{Quadro 1}

Perfil dos hábitos de vida dos idosos

\begin{tabular}{|c|c|c|c|c|c|c|c|c|c|}
\hline Local & Resposta & Dança & Exercícios & Cantar & Conversa & Música & Teatro & Família & Namorar \\
\hline \multirow{2}{*}{1} & $\operatorname{Sim}(\%)$ & 33,3 & 66,7 & 33,3 & 46,7 & 66,7 & 40 & 33,3 & 33,3 \\
\hline & Não (\%) & 66,7 & 33,3 & 66,7 & 53,3 & 33,3 & 60 & 66,7 & 66,7 \\
\hline \multirow{2}{*}{2} & Sim (\%) & 73,3 & 66,7 & 33,3 & 46,7 & 66,7 & 13,3 & 60 & 20 \\
\hline & Não (\%) & 26,7 & 33,3 & 66,7 & 53,3 & 33,3 & 86,7 & 40 & 80 \\
\hline
\end{tabular}

\begin{tabular}{|c|c|c|c|c|c|c|c|c|c|}
\hline Local & Resposta & Shows & Cinema & Viajar & Caminhar & Dormir & Pintar & Cursos & Abraçar \\
\hline \multirow{2}{*}{1} & $\operatorname{Sim}(\%)$ & 53,3 & 53,3 & 93,3 & 60 & 46,7 & 0 & 53,3 & 46,7 \\
\hline & Não (\%) & 46,7 & 46,7 & 6,7 & 40 & 53,3 & 100 & 46,7 & 53,3 \\
\hline \multirow{2}{*}{2} & Sim (\%) & 13,3 & 20 & 80 & 73,3 & 53,3 & 20 & 40 & 73,3 \\
\hline & Não (\%) & 86,7 & 80 & 20 & 26,7 & 46,7 & 80 & 60 & 26,7 \\
\hline Local & Resposta & $\begin{array}{l}\text { Obras } \\
\text { Sociais }\end{array}$ & Passear & Costurar & Rezar & Bordar & Leitura & $\begin{array}{l}\text { Redes } \\
\text { Sociais }\end{array}$ & Beijar \\
\hline \multirow{2}{*}{1} & $\operatorname{Sim}(\%)$ & 26,7 & 66,7 & 20 & 66,7 & 20 & 80 & 53,3 & 13,3 \\
\hline & Não (\%) & 73,3 & 33,3 & 80 & 33,3 & 80 & 20 & 46,7 & 86,7 \\
\hline \multirow{2}{*}{2} & $\operatorname{Sim}(\%)$ & 26,7 & 66,7 & 13,3 & 60 & 6,7 & 66,7 & 33,3 & 20 \\
\hline & Não (\%) & 73,3 & 33,3 & 86,7 & 40 & 93,3 & 33,3 & 66,7 & 80 \\
\hline
\end{tabular}

\begin{tabular}{|c|c|c|c|c|c|c|c|c|c|}
\hline Local & Resposta & Aprender & Descansar & Grupos & Novelas & Idiomas & Jogos & Presentes & Reportagem \\
\hline \multirow{2}{*}{1} & Sim (\%) & 66,7 & 33,3 & 60 & 40 & 40 & 40 & 53,3 & 60 \\
\hline & Não (\%) & 33,3 & 66,7 & 40 & 60 & 60 & 60 & 46,7 & 40 \\
\hline \multirow{2}{*}{2} & $\operatorname{Sim}(\%)$ & 86,7 & 40 & 53,3 & 53,3 & 6,7 & 40 & 46,7 & 40 \\
\hline & Não (\%) & 13,3 & 60 & 46,7 & 46,7 & 93,3 & 60 & 53,3 & 60 \\
\hline
\end{tabular}

\begin{tabular}{|c|c|c|c|c|c|c|c|c|c|}
\hline Local & Resposta & Sozinho & Conhecido & Amigos & $\begin{array}{l}\text { Casa } \\
\text { Filho }\end{array}$ & $\begin{array}{l}\text { Grupos } \\
\text { Sociais }\end{array}$ & Animal & $\begin{array}{c}\text { Lar } \\
\text { Idosos }\end{array}$ & Cuidador \\
\hline \multirow{2}{*}{1} & Sim (\%) & 46,7 & 13,3 & 80 & 40 & 60 & 13,3 & 0 & 0 \\
\hline & Não (\%) & 53,3 & 86,7 & 20 & 60 & 40 & 86,7 & 100 & 100 \\
\hline \multirow{2}{*}{2} & Sim (\%) & 40 & 13,3 & 26,7 & 33,3 & 33,3 & 20 & 6,7 & 0 \\
\hline & Não (\%) & 60 & 86,7 & 73,3 & 66,7 & 66,7 & 80 & 93,3 & 100 \\
\hline
\end{tabular}




\begin{tabular}{|c|c|c|c|c|c|c|c|c|}
\hline Local & Resposta & Netos & Vizinho & Passeando & Trabalhando & $\begin{array}{l}\text { Fazendo } \\
\text { Cursos }\end{array}$ & $\begin{array}{l}\text { Ajuda } \\
\text { outros }\end{array}$ & $\begin{array}{c}\text { Em ativi- } \\
\text { dade }\end{array}$ \\
\hline \multirow{2}{*}{1} & $\operatorname{Sim}(\%)$ & 26,7 & 6,7 & 53,3 & 33,3 & 46,7 & 33,3 & 53,3 \\
\hline & Não (\%) & 73,3 & 93,3 & 46,7 & 66,7 & 53,3 & 66,7 & 46,7 \\
\hline \multirow{2}{*}{2} & $\operatorname{Sim}(\%)$ & 26,7 & 6,7 & 26,7 & 46,7 & 20 & 46,7 & 66,7 \\
\hline & Não (\%) & 73,3 & 93,3 & 73,3 & 53,3 & 80 & 53,3 & 33,3 \\
\hline
\end{tabular}

\section{* 1: Instituição 1; 2: Instituição 2. \%: representa a frequência (\%), e foi apresentado em negrito os valores significativos.}

Através do questionário, portanto, foi possível obter os dados da população em estudo, proveniente das duas instituições - a ONG e o clube social -, entre os meses de junho e setembro de 2019. Houve a ideia de pesquisar como funcionam os locais em que esses idosos costumam circular, como são acolhidos e de que forma os profissio- nais da saúde e ocupacional atuam com eles, inserindo-os nos diversos espaços disponíveis, a fim de verificar os mecanismos do funcionamento social e familiar, apontando dificuldades em relação a deslocamentos, segurança, saúde etc. (Quadro 2).

\section{Quadro 2}

Perfil da funcionalidade social e familiar dos idosos

\begin{tabular}{|c|c|c|c|c|c|c|c|}
\hline Local & Resposta & Desrespeito & Filas & $\begin{array}{l}\text { Suprir Necessi- } \\
\text { dades }\end{array}$ & Ofensas & Solidão & Indiferença \\
\hline \multirow{2}{*}{1} & $\operatorname{Sim}(\%)$ & 66,7 & 6,7 & 86,7 & 20 & 6,7 & 53,3 \\
\hline & Não (\%) & 33,3 & 93,3 & 13,3 & 80 & 93,3 & 46,7 \\
\hline \multirow{2}{*}{2} & $\operatorname{Sim}(\%)$ & 73,3 & 33,3 & 93,3 & 26,7 & 33,3 & 33,3 \\
\hline & Não (\%) & 26,7 & 66,7 & 6,7 & 73,3 & 66,7 & 66,7 \\
\hline
\end{tabular}

\begin{tabular}{|c|c|c|c|c|c|c|c|}
\hline Local & Resposta & Adaptação & Dificuldades & Desprezo & Impaciência & $\begin{array}{l}\text { Tempo } \\
\text { Ocioso }\end{array}$ & Agitação \\
\hline \multirow{2}{*}{1} & $\operatorname{Sim}(\%)$ & 0 & 6,7 & 40 & 40 & 20 & 13,3 \\
\hline & Não (\%) & 100 & 93,3 & 60 & 60 & 80 & 86,7 \\
\hline \multirow{2}{*}{2} & $\operatorname{Sim}(\%)$ & 6,7 & 20 & 6,7 & 20 & 13,3 & 26,7 \\
\hline & Não (\%) & 93,3 & 80 & 93,3 & 80 & 86,7 & 73,3 \\
\hline
\end{tabular}

\begin{tabular}{cccccccc}
\hline Local & Resposta & Doenças & Transporte & Lojas especiais & Proteção & $\begin{array}{c}\text { Adap. } \\
\text { Local }\end{array}$ & Enfermagem \\
\hline \multirow{2}{*}{1} & Sim (\%) & 40 & 33,3 & 0 & 6,7 & 20 & 0 \\
\hdashline & Não (\%) & $\mathbf{6 0}$ & $\mathbf{6 6 , 7}$ & $\mathbf{1 0 0}$ & $\mathbf{9 3 , 3}$ & $\mathbf{8 0}$ & $\mathbf{1 0 0}$ \\
\hline & Sim (\%) & $\mathbf{6 6 , 7}$ & 20 & 6,7 & 6,7 & 0 & 0 \\
\hdashline Não (\%) & 33,3 & $\mathbf{8 0}$ & $\mathbf{9 3 , 3}$ & $\mathbf{9 3 , 3}$ & $\mathbf{1 0 0}$ & $\mathbf{1 0 0}$
\end{tabular}




\begin{tabular}{rccccccc}
\hline Local & Resposta & UBS & Clínicas & Nutrição & Exercícios & Acompanhante & Medicamentos \\
\hline \multirow{2}{*}{1} & $\operatorname{Sim}(\%)$ & 6,7 & 0 & 6,7 & 20 & 13,3 & 13,3 \\
& Não (\%) & $\mathbf{9 3 , 3}$ & $\mathbf{1 0 0}$ & $\mathbf{9 3 , 3}$ & $\mathbf{8 0}$ & $\mathbf{8 6 , 7}$ & $\mathbf{8 6 , 7}$ \\
\hdashline & $\operatorname{Sim}(\%)$ & $\mathbf{6 6 , 7}$ & 6,7 & 6,7 & 0 & 13,3 & 40 \\
\hline & Não (\%) & 33,3 & $\mathbf{9 3 , 3}$ & $\mathbf{9 3 , 3}$ & $\mathbf{1 0 0}$ & $\mathbf{8 6 , 7}$ & $\mathbf{6 0}$
\end{tabular}

\begin{tabular}{|c|c|c|c|c|c|c|c|}
\hline Local & Resposta & Assistência & Psicólogo & Farmácia & Debilidades & Segurança & $\begin{array}{l}\text { Hosp. / } \\
\text { Médicos }\end{array}$ \\
\hline \multirow{2}{*}{1} & $\operatorname{Sim}(\%)$ & 13,3 & 0 & 0 & 20 & 53,3 & 20 \\
\hline & Não (\%) & 86,7 & 100 & 100 & 80 & 46,7 & 80 \\
\hline \multirow{2}{*}{2} & $\operatorname{Sim}(\%)$ & 0 & 13,3 & 20 & 6,7 & 73,3 & 46,7 \\
\hline & Não (\%) & 100 & 86,7 & 80 & 93,3 & 26,7 & 53,3 \\
\hline
\end{tabular}

\begin{tabular}{rcccc}
\hline Local & Resposta & Psiquiatra & Fisioterapia & Bons profissionais \\
\hline 1 & $\operatorname{Sim}(\%)$ & $\mathbf{6 , 7}$ & $\mathbf{6 , 7}$ & 13,3 \\
\hline & Não (\%) & $\mathbf{9 3 , 3}$ & $\mathbf{9 3 , 3}$ & $\mathbf{8 6 , 7}$ \\
\hdashline $\operatorname{Sim}(\%)$ & $\mathbf{6 , 7}$ & $\mathbf{6 , 7}$ & 33,3 \\
\hline 2 & Não (\%) & $\mathbf{9 3 , 3}$ & $\mathbf{9 3 , 3}$ & $\mathbf{6 6 , 7}$ \\
\hline
\end{tabular}

* 1: Instituição 1; 2: Instituição 2. \%: representa a frequência (\%), e foi apresentado em negrito os valores significativos.

Foram possibilitados vários contatos nos locais de pesquisa. Os idosos se sentiram desprovidos de preconceitos e fizeram inúmeros questionamentos (que exigiram estarmos informados e até opinarmos segundo o nosso olhar) e muitos relatos sobre as suas peculiaridades. Também foi possível conhecer os modos de proceder dos profissionais que ali atuam e, ainda, dos processos ligados ao ambiente físico-estrutural. A ONG, mesmo com recursos escassos, empenha-se para tornar agradáveis todos os momentos de convívio das pessoas idosas, que recebem ali, inclusive, tratamento psicológico sem custos, de acordo com a sua necessidade ou vontade (que entrou em vigor a partir da pesquisa). Os idosos estão muito familiarizados com esse ambiente, são assíduos e não poupam em compartilhar os seus conhecimentos, até mesmo lançam convites uns aos outros para frequentarem suas casas e fazerem trocas das habilidades que possuem. Nos aniversários, o grupo é solidário e trazem doces e salgados para confraternizar entre amigos, além das trocas de presentes. O clube social também faz homenagem aos idosos nos aniversários e a equipe responsável pela assistência e atividades conhece cada integrante pelo nome e suas histórias, tornando único cada momento de convívio. Dessa forma, encaixa-se nesses contextos de trocas e busca de sentido algo estruturante, que denominamos perspectivas de vida e futuro, inserindo os projetos pessoais cujos resultados podem ser comparados e verificados abaixo (Quadro 3). 
Quadro 3

Perfil das perspectivas de vida e futuro dos idosos

\begin{tabular}{|c|c|c|c|c|c|c|c|c|}
\hline Local & Resposta & Infância & Adolescência & Juventude & $\begin{array}{c}\text { Atuação } \\
\text { profissional }\end{array}$ & $\begin{array}{l}\text { Constituição } \\
\text { familiar }\end{array}$ & $\begin{array}{c}\text { Período } \\
\text { acadêmico }\end{array}$ & $\begin{array}{c}\text { Amadureci- } \\
\text { mento }\end{array}$ \\
\hline \multirow{2}{*}{1} & Sim (\%) & 46,7 & 13,3 & 40 & 40 & 73,3 & 26,7 & 73,3 \\
\hline & Não (\%) & 53,3 & 86,7 & 60 & 60 & 26,7 & 73,3 & 26,7 \\
\hline \multirow{2}{*}{2} & $\operatorname{Sim}(\%)$ & 33,3 & 26,7 & 66,7 & 20 & 20 & 26,7 & 66,7 \\
\hline & Não (\%) & 66,7 & 73,3 & 33,3 & 80 & 80 & 73,3 & 33,3 \\
\hline
\end{tabular}

\begin{tabular}{|c|c|c|c|c|c|c|c|c|}
\hline Local & Resposta & Conhecimento & Sabedoria & $\begin{array}{l}\text { Decisões } \\
\text { acertadas }\end{array}$ & $\begin{array}{l}\text { Direito a } \\
\text { ensino }\end{array}$ & Experiência & $\begin{array}{c}\text { Tempo de } \\
\text { vida }\end{array}$ & $\begin{array}{c}\text { Proximidade } \\
\text { da morte }\end{array}$ \\
\hline \multirow{2}{*}{1} & $\operatorname{Sim}(\%)$ & 73,3 & 60 & 26,7 & 26,7 & 66,7 & 46,7 & 6,7 \\
\hline & Não (\%) & 26,7 & 40 & 73,3 & 73,3 & 33,3 & 53,3 & 93,3 \\
\hline \multirow{2}{*}{2} & $\operatorname{Sim}(\%)$ & 66,7 & 60 & 26,7 & 53,3 & 80 & 40 & 13,3 \\
\hline & Não (\%) & 33,3 & 40 & 73,3 & 46,7 & 20 & 60 & 86,7 \\
\hline
\end{tabular}

\begin{tabular}{|c|c|c|c|c|c|c|c|c|}
\hline Local & Resposta & $\begin{array}{l}\text { Rever } \\
\text { amigos }\end{array}$ & $\begin{array}{c}\text { Convivio } \\
\text { social }\end{array}$ & $\begin{array}{l}\text { Coisas } \\
\text { legais }\end{array}$ & Informática & Coisas novas & Trabalho & Interagir \\
\hline \multirow{2}{*}{1} & Sim (\%) & 66,7 & 73,3 & 46,7 & 6,7 & 26,7 & 6,7 & 20 \\
\hline & Não (\%) & 33,3 & 26,7 & 53,3 & 93,3 & 73,3 & 93,3 & 80 \\
\hline \multirow{2}{*}{2} & $\operatorname{Sim}(\%)$ & 46,7 & 46,7 & 73,3 & 33,3 & 80 & 26,7 & 33,3 \\
\hline & Não (\%) & 53,5 & 53,3 & 26,7 & 66,7 & 20 & 73,3 & 66,7 \\
\hline
\end{tabular}

\begin{tabular}{rccccc}
\hline Local & Resposta & Alimentação & Idioma & Saúde & Obras sociais \\
\hline \multirow{2}{*}{1} & Sim (\%) & 40 & 20 & 40 & 40 \\
& Não (\%) & 60 & 80 & 60 & 60 \\
& Sim (\%) & 40 & 33,3 & 66,7 & 26,7 \\
& Não (\%) & 60 & 66,7 & 33,3 & 73,3
\end{tabular}

* 1: Instituição 1; 2: Instituição 2. \%: representa a frequência (\%), e foi apresentado em negrito os valores significativos.

Os nossos achados demonstram com clareza que os idosos percebem a existência de espaços de acolhimento e expressão, mas, em sua maioria, sinalizam a restrição e deixam claro que há muito a ser feito para que as pessoas dessa faixa etária possam se sentir inseridas em um contexto considerado ideal. Ficou claro que grande parte dos idosos prefere continuar com novas perspectivas e tenta se eximir da conformidade (motivo pelo qual exploramos os diferentes modos relacionados aos idosos: como este funciona, o que considera importante, pessoas e locais de suporte e quais as lacunas que existem para a sua felicidade, bem-estar e conforto) ou em continuar vivendo de acordo com a realidade que lhes é oferecida ou imposta, ao que se deve, consequentemente, exigir das autoridades responsáveis maior atuação a fim de favorecer a qualidade de vida ativa e contínua no processo de envelhecimento. Logo, percebemos através desse estudo que os idosos se autodesafiam em busca de novas descobertas, por mais que no decurso da idade surjam limitações que acabam gerando novos modos a fim de poderem conviver com a ideia de que nem tudo é da forma que desejam e possível realizar como antes, mas que pode ser feito de outro jeito (Quadro 4). 


\section{Quadro 4}

Caracterização dos desafios e limitações dos idosos

\begin{tabular}{|c|c|c|c|c|c|c|c|}
\hline Local & Resposta & Tato & Memória & Olfato & Debilidade & Visão & Paladar \\
\hline \multirow{2}{*}{1} & $\operatorname{Sim}(\%)$ & 0 & 13,3 & 0 & 6,7 & 20 & 0 \\
\hline & Não (\%) & 100 & 86,7 & 100 & 93,3 & 80 & 100 \\
\hline \multirow{2}{*}{2} & $\operatorname{Sim}(\%)$ & 0 & 33,3 & 0 & 6,7 & 46,7 & 0 \\
\hline & Não (\%) & 100 & 66,7 & 100 & 93,3 & 53,3 & 100 \\
\hline Local & Resposta & Audição & Saúde & Passado & Presente & Futuro & Projetos \\
\hline \multirow{2}{*}{1} & $\operatorname{Sim}(\%)$ & 46,7 & 13,3 & 0 & 0 & 0 & 60 \\
\hline & Não (\%) & 53,3 & 86,7 & 0 & 0 & 0 & 40 \\
\hline \multirow{2}{*}{2} & $\operatorname{Sim}(\%)$ & 26,7 & 53,3 & 0 & 0 & 0 & 66,7 \\
\hline & Não (\%) & 73,3 & 46,7 & 0 & 0 & 0 & 26,7 \\
\hline Local & Resposta & SUS & Particular & Outros & Bom & Regular & Ruim \\
\hline \multirow{2}{*}{1} & $\operatorname{Sim}(\%)$ & 0 & 53,3 & 60 & 93,3 & 13,3 & 0 \\
\hline & Não (\%) & 100 & 46,7 & 40 & 6,7 & 86,7 & 100 \\
\hline \multirow{2}{*}{2} & $\operatorname{Sim}(\%)$ & 53,3 & 26,7 & 26,7 & 60 & 40 & 6,7 \\
\hline & Não (\%) & 46,7 & 73,3 & 73,3 & 40 & 60 & 93,3 \\
\hline
\end{tabular}

* 1: Instituição 1; 2: Instituição 2. \%: representa a frequência (\%), e foi apresentado em negrito os valores significativos.

Os idosos participantes da pesquisa, no âmbito geral, acreditam que o programa esteja fazendo muito bem a eles, pois percebem, nesses locais, uma extensão de seus lares, onde conhecem novos amigos, que acabam fazendo parte de suas vidas. As instituições passam a ser algo visceral, havendo uma necessidade de frequentar os locais semanalmente para encontrar pessoas queridas e com quem podem compartilhar os acontecimentos da vida pessoal, trocar ideias sobre o social, desabafar trazendo questões que causam desconforto, fazendo novas descobertas, e até relembrar fatos da vida, algo que seja constituinte. Nas atividades práticas são feitas trocas interessantes nas quais os idosos se divertem, sentem prazer em aprender e ensinar, poder dizer que já foram muito importantes em algum momento em que tiveram um cargo profissional, que conseguiram administrar todas as questões relacionadas aos seus lares, tiveram grandes amores, conviveram com amigos queridos que já partiram ou que vivem agora em outros lugares. Enfim, as instituições são a representação de um lugar que faz bem, onde se interage, aprende e se sente prazer no convívio. Arriscamos dizer que esses lugares são, em parte, a ideia de repúblicas (convívio em comunidades) vinda da Dinamarca, e que se faz perceber, no momento atual, como possibilidade de evitar a solidão e estar em um ambiente de iguais. Nesta última dimensão, os idosos refletiram e responderam sobre os sentidos da participação do programa (Quadro 5). 


\section{Quadro 5}

Caracterização do sentido da participação dos idosos no programa pesquisado

\begin{tabular}{|c|c|c|c|c|c|c|c|c|c|}
\hline Local & Resposta & Culturais & Artísticas & Educativas & $\begin{array}{l}\text { Oficinas de } \\
\text { arte }\end{array}$ & Finanças & Informática & Alfabetização & Origami \\
\hline \multirow{2}{*}{1} & $\operatorname{Sim}(\%)$ & 80 & 40 & 40 & 13,3 & 0 & 6,7 & 0 & 40 \\
\hline & Não (\%) & 20 & 60 & 60 & 86,7 & 100 & 93,3 & 100 & 60 \\
\hline & $\operatorname{Sim}(\%)$ & 0 & 0 & 6,7 & 6,7 & 33,3 & 6,7 & 0 & 0 \\
\hline & Não (\%) & 100 & 100 & 93,3 & 93,3 & 66,7 & 93,3 & 100 & 100 \\
\hline
\end{tabular}

\begin{tabular}{cccccccccc}
\hline Local & Resposta & Ginástica & Passeios & Esportes & Dinâmica & Lazer & Convivência & Diversão & Confraternização \\
\hline 1 & Sim (\%) & 40 & 80 & 6,7 & 20 & 40 & 66,7 & 33,3 & 60 \\
& Não (\%) & 60 & 20 & 93,3 & 80 & 60 & 33,3 & 66,7 & 40 \\
\hdashline & Sim (\%) & 100 & 60 & 13,3 & 6,7 & 20 & 66,7 & 26,7 & 80 \\
2 & Não (\%) & 0 & 40 & 86,7 & 93,3 & 80 & 33,3 & 73,3 & 20
\end{tabular}

\begin{tabular}{|c|c|c|c|c|c|c|c|c|c|}
\hline Local & Resposta & Palestras & $\begin{array}{l}\text { Trabalho } \\
\text { comunitário }\end{array}$ & $\begin{array}{l}\text { Vínculo } \\
\text { idoso }\end{array}$ & $\begin{array}{c}\text { Práticas } \\
\text { sociais }\end{array}$ & $\begin{array}{c}\text { Que te } \\
\text { faz bem }\end{array}$ & Indicação & Te informou & Por acaso \\
\hline \multirow{2}{*}{1} & $\operatorname{Sim}(\%)$ & 0 & 13,3 & 40 & 26,7 & 100 & 33,3 & 13,3 & 40 \\
\hline & Não (\%) & 100 & 86,7 & 60 & 73,3 & 0 & 66,7 & 86,7 & 60 \\
\hline & $\operatorname{Sim}(\%)$ & 6,7 & 13,3 & 80 & 6,7 & 93,3 & 60 & 6,7 & 33,3 \\
\hline & Não (\%) & 93,3 & 86,7 & 20 & 93,3 & 6,7 & 40 & 93,3 & 66,7 \\
\hline
\end{tabular}

\begin{tabular}{ccccccccc}
\hline Local & Resposta & Outros & $\begin{array}{c}\text { Estar com } \\
\text { amigos }\end{array}$ & Sinto bem & Aprender & Sair de casa & Falar da Vida & Conv. Iguais \\
\hline & Sim (\%) & 20 & 73,3 & 93,3 & 60 & 26,7 & 6,7 & 60 \\
\hline & Não (\%) & 80 & 26,7 & 6,7 & 40 & 73,3 & 93,3 & 40 \\
\hdashline & Sim (\%) & 20 & 73,3 & 73,3 & 53,3 & 40 & 46,7 & 66,7 \\
\hline 2 & Não (\%) & 80 & 26,7 & 26,7 & 46,7 & 60 & 53,3 & 33,3 \\
\hline
\end{tabular}

* 1: Instituição 1; 2: Instituição 2. \%: representa a frequência (\%), e foi apresentado em negrito os valores significativos

Considera-se, outrossim, que a presente pesquisa tenha sido positiva, no que diz respeito à análise comparativa dos idosos em espaços sociais, uma vez que os resultados vieram a confirmar as hipóteses iniciais, assim como o estudo proporcionou o despertar de novas ideias, e as próprias pessoas idosas manifestaram-se surpresas ao se perceberem envoltas por questões sobre as quais não haviam refletido anteriormente. As instituições demonstram procedimentos semelhantes na forma de agir e no tratamento dado às pessoas idosas, estando plenamente comprometidas em primar pela maior qualidade de vida das pessoas idosas, as quais são acolhidas e valorizadas nesses ambientes, evitando, assim, os processos depressivos causados pela solidão e encontrando, nessa inclusão, um verdadeiro sentido para continuar vivendo e se sentindo inseridas no contexto social. Nesses locais se forma uma grande família, que convivem e acabam criando verdadeiros vínculos. 


\section{Considerações Finais}

Constatamos a importância da pesquisa, que explorou o tema de forma intensa e levantou, inclusive, questões que estavam obscuras e sobre as quais ainda não se tinha muita clareza. Assim, o estudo trouxe benefícios às pessoas idosas, visto que possibilitou ampliar horizontes quanto ao processo do envelhecimento e conscientizou sobre as disponibilidades existentes nos ambientes sociais, e também sobre as fragilidades ou necessidades que não estão sendo supridas. Toda a pesquisa foi pensada e direcionada para as vivências práticas das pessoas idosas: as possibilidades existentes e as lacunas; as necessidades e os quesitos que consideram bem supridos; a assistência desde familiar até social; as políticas que as envolvem; a percepção do próprio idoso dentro de um contexto em que está delineando a continuidade da vida e até o seu futuro. Isso ampliou a sua visão e fez com que percebessem de que a vida continua e que existem diferentes modos de estar e sentirem-se inseridos nos contextos.

As instituições, por sua vez, puderam refletir sobre as suas práticas para com os idosos e explorar novas possibilidades, que foram claramente perceptíveis a partir de então (uma vez que obtiveram o retorno desta pesquisa após terem sido gerados os resultados, possibilitando a discussão, elas conseguiram refletir sobre novos modos e adaptações que julgaram ser viáveis e comprometeram-se a buscar soluções nas diversas lacunas que foram surgindo), no que tange à busca de recursos para melhorar os espaços, disponibilizar mais horários e entretenimento, ouvir mais o que as pessoas idosas têm a dizer. $\mathrm{E}$, como resultado da pesquisa, a ONG passou a disponibilizar atendimento psicológico, havendo busca de voluntários para ministrarem palestras sobre diferentes temas, entre outros.

A falta de recursos e pouco interesse dos órgãos responsáveis são percebidos principalmente na ONG, onde as estruturas são precárias, as equipes são em sua maioria voluntários e fazem de tudo o que está ao alcance para atenderem as expectativas e necessidades dos idosos. 0 clube social está mais organizado devido ao movimento existir há muito tempo e os gestores disponibilizarem recursos que favoreçam as pessoas idosas, e porque ali os idosos pagam uma pequena taxa mensal para podem usufruir dos benefícios.

Portanto, ficou evidente a importância do constante aperfeiçoamento e ampliação, mas também de que sempre haverá questões que emergem e devem ser sanadas em prol dos idosos. Certamente, tudo envolve recursos financeiros e questões políticas que levam à prorrogação e acabam fazendo com que existam muitas promessas que não são cumpridas e, supostamente, ficam no esquecimento. Esta pesquisa aprofundou o conhecimento, mudou a visão sobre inúmeros assuntos estudados e, também, ampliou o senso crítico científico, aspectos estes que farão a diferença na capacitação, principalmente no que tange à interdisciplinaridade entre as ciências da saúde, relevante nos objetivos estudados.

\section{Referências}

Almeida, M. L. P. (1996). Tipos de pesquisa: como elaborar monografias (4a ed. rev. e atual). Cejup.

Barsi Filho, H. C. C., Leal, J. C. G. P. S., Pessoa, J. C. S., \& Portela, J. A. (2015). Visão da equipe multidisciplinar do clube da pessoa idosa quanto ao envelhecimento ativo. Anais CIEH, 2(1), 1-6. http://www.editorarealize. com.br/revistas/cieh/trabalhos/TRABALHO_EV040 MD4_SA15_ID2404_27082015215727.pdf.

Bastos, J. L. D., \& Duquia, R. P. (2007). Um dos delineamentos mais empregados em epidemiologia: estudo transversal. Scientia Medica, Porto Alegre, 17(4), 229232. http://revistaseletronicas.pucrs.br/ojs/index. php/\%20scientiamedica/article/viewFile/2806/2634.

Besse, M., Cecílio, L. C. O., \& Lemos, N. D (2014). A Equipe Multiprofissional em Gerontologia e a Produção do Cuidado: um estudo de caso. Revista Kairós Gerontologia, 17(2), 205-222.

Booth, W. C. A arte da pesquisa ( 2 a ed.). Martins Fontes, 2005.

Carboni R. M., \& Reppetto M. A. (2007). Uma reflexão sobre a assistência à saúde do idoso no Brasil. Revista Eletrônica de Enfermagem, 9(1), 251-60. http://www. fen.ufg.br/revista/v9/n1/v9n1a20.htm.

Castiel, C. Z (2016). Transição Demográfica no Brasil: perspectivas e desafios: um breve ensaio. 1-43. http:// www.econ.pucrio.br/uploads/adm/trabalhos/files/ Carolina_Zucchi_Castiel.pdf.

Gil, A. C. (2009). Como elaborar projetos de pesquisas (4a ed.). Atlas.

Gordis, L. (2017). Epidemiologia. Editora Revinter.

Guerra, J. C. A., Freire, T. V. V., Ramos, D. K. R., Paiva, R. M. O. A. S, \& Kalache, A. (2008). O mundo enveIhece: é imperativo criar um pacto de solidariedade 
social. Ciênc. Saúde Coletiva, 13(4), 1107-11. http:// www.scielo.br/scielo.php?script=sci_arttext\&pi$d=S 1413-81232008000400002$.

Guerra, J. C. A., Freire, T. V. V., Ramos, D. K. R., Paiva R. M. O. A. S, \& Câmara, Y. P. (2013). Principais formas de inclusão social da pessoa idosa: revisitando a literatura científica. Anais CIEH, Campina Grande, PB, 1-2. http://www.editorarealize.com.br/revistas/cieh/trabalhos/Poster_idinscrito_480_665b20bc7536f05444 ac191a90024434.pdf.

Lei no 10.741 , de $1^{\circ}$ de outubro de 2003. Dispõe sobre o Estatuto do Idoso e dá outras providências. http:// www.planalto.gov.br/ccivil_03/leis/2003//10.741. htm.

Lopes, P. A. (1999). Probabilidade \& Estatística. Reichman \& Affonso Editores.

Maia, D. B., Sousa, E. T. G., Gama, R. M., Lima, J. C., Farias Rocha, P. C., \& Sassaki, Y. (2013). Atuação interdisciplinar na Atenção Básica de Saúde: a inserção da Residência Multiprofissional. Saúde \& Transformação Social, 4(1), 103-110. http://incubadora.periodicos.ufsc.br/index.php/saudeetransformacao/article/ view/1825

Neri, A. L. (Org.). (2001). Desenvolvimento e envelhecimento: perspectivas biológicas, psicológicas e sociológicas. Papirus.

Organização Mundial de Saúde - OMS. (2015) Relatório Mundial de Saúde. Genebra. https://apps.who.int/ iris/bitstream/handle/10665/186468/WHO_FWC_ ALC_15.01_por.pdf;js
Peduzzi, M. Trabalho em equipe. In: Lima, J. C. F., \& Pereira, I. B. (Orgs.). (2009). Dicionário de educação profissional em saúde. 2. ed. EPSJV. p. 419-426.

Pereira, M. G. (1995). Epidemiologia: teoria e prática. Guanabara Koogan.

Silva, I. Z.; Trad, L. A. (2005). O trabalho em equipe no PSF: investigando a articulação técnica e interação entre os profissionais. Interface, 9(16), 25-38. http:// www.scielo.br/scielo.php?script $=$ sci_abstract \&pi$\mathrm{d}=$ S1414-32832005000100003\& Ing=en\&nrm=iso\&tl$\mathrm{ng}=\mathrm{pt}$.

Torres, M. M., \& Santos Sá, M. A. Á. dos. (2008). Inclusão social de idosos: um longo caminho a percorrer. Revista Ciências Humanas - Universidade de Taubaté (UNITAU), Brasil, 1(2), 1-10.

Vasconcelos, A. M. N., \& Gomes, M. M. F. (2012). Transição demográfica: a experiência brasileira. Epidemiologia e Serviço em Saúde, 21(4), 1-10. http://dx.doi. org/10.5123/S1679-49742012000400003.

Whitaker, D. C. A. (2010, mai-ago). O idoso na contemporaneidade: a necessidade de se educar a sociedade para as exigências desse "novo" ator social, titular de direitos. Cad. CEDES, Campinas, 30(81), 179-188, mai.-ago. 2010. https://doi.org/10.1590/S0101-3262201 0000200004. 